\title{
The Model of eSports Ecosystems
}

\author{
Piotr ŚLIWA * and Grzegorz KRZOS
}

Wrocław University of Economics and Business, Wrocław, Poland; piotr.sliwa@ue.wroc.pl; grzegorz.krzos@ue.wroc.pl

* Correspondence: piotr.sliwa@ue.wroc.pl

\begin{abstract}
Electronic sports, widely known as eSports, are presumably the most profound evolutionary movement of the sports industry in the modern history. Despite the business potential, though, the eSports industry remains relatively unexplored in the literature of the management discipline, especially from the network perspective. To fill the gap confirmed in the literature review, the research aimed at answering a question regarding the contents of eSports ecosystems - who the actors are and how do they interact with each other. A multiple case study was carried out, involving content analysis of social media posts published by a selection of eSports-related organizations in order to identify and classify entities comprising the eSports networks. As a result, the authors proposed and described a network model of the eSports ecosystems consisting of distinct roles (stakeholders) and relationships observed in ego-networks of the investigated entities. The model can serve as a foundation for future research on the eSports ecosystems and provide a bird-view on the industry's mode of work for practitioners.
\end{abstract}

Keywords: esports; electronic sports; network analysis; ecosystem; business model; business model innovation

JEL Classification: M10; M13

\section{Introduction}

Electronic sports, widely known as eSports, are presumably the most profound evolutionary movement of the sports industry in the modern history. They break the majority of rules that are conventionally bound to the competition between athletes - the rules of physics and the limitations of human body. In case of the eSports, the only limitations of the game mechanics are the ones introduced by a game developer or a modder (typically an independent developer who modifies a game's source in order to change its look, mechanics, etc.). The liberation has been gaining popularity and fueling the economic activities on an unprecedented scale, reportedly reaching growth of over $40 \%$ on a year-toyear basis and generating around $\$ 700$ million in revenue with the audience of over 385 million people by the end of 2017 (Newzoo 2017). Two years later, in a new report the same company estimated that the eSports industry would generate $\$ 1.1$ billion in revenue, growing at a still magnificent pace of $+26.7 \%$ year-to-year with the audience of over 453 million people (Newzoo 2019). Furthermore, the eSports are progressively considered to be merged into the major traditional sport events like the Olympics (IOC 2018) and Asian Games (BBC 2017) as one of the contested disciplines.

Despite the business potential the eSports industry remains relatively unexplored in the literature of the management discipline, especially from the network perspective. A review of currently available business and management articles resulted in their abstract-based classification presented in Chyba! Nenalezen zdroj odkazů.. A list of the literature positions was extracted from the Scopus database by querying it with two keywords - "eSports" and "electronic sports" - and subsequently narrowing the search scope to the "Business, Management and Accounting" subject area. Subsequently, they were classified to a specific theme based on their title, abstract and keywords. The goal of the review was to identify the existing literature describing the eSports business networks so only articles from the "network analysis" theme was subject to further content analysis. 
Table 1. Classification of the eSports studies from the "Business, Management and Accounting" subject area, listed in the Scopus database.

\begin{tabular}{ccc}
\hline Theme & Description & $\begin{array}{c}\text { No. } \\
\text { identified } \\
\text { articles }\end{array}$ \\
\hline $\begin{array}{c}\text { Player and } \\
\text { consumer } \\
\text { behavior }\end{array}$ & $\begin{array}{c}\text { Studies researching motives, behavior, etc. of players, } \\
\text { spectators and other eSports consumers. }\end{array}$ & 14 \\
$\begin{array}{c}\text { General } \\
\text { discussion }\end{array}$ & $\begin{array}{c}\text { Studies touching upon miscellaneous eSports aspects (e.g. } \\
\text { eSports statistics, differences between sports and eSports, } \\
\text { etc.). }\end{array}$ & 8 \\
$\begin{array}{c}\text { Network } \\
\text { analysis }\end{array}$ & $\begin{array}{c}\text { Studies describing the eSports industry from the network } \\
\text { perspective, particularly analyzing the eSports business } \\
\text { networks and phenomena occurring within them. }\end{array}$ & 3 \\
Law & $\begin{array}{c}\text { Studies dedicated to various legal challenges of the eSports } \\
\text { industry. }\end{array}$ & 2 \\
\hline
\end{tabular}

The recent book by Scholz (2019) summarized the current state of knowledge from the strategic management's perspective on the eSports industry. The author used the stakeholder journey approach in order to identify and characterize the eSports industry's stakeholders, dividing them into two groups in accordance to the division proposed by Darnall et al. (2010):

- primary stakeholders directly involved in the value chain - game developers, tournament organizers, professional players and teams, infrastructure and service providers, community,

- secondary stakeholders who have an indirect influence on the primary stakeholders, serving as their environment - governing bodies, sports organizations, sponsors, the general public, investors, entrepreneurs, media and others (Scholz 2019).

The author also elaborated on governing principles and business models observed in the eSports industry, concluding with the sector's forecasted roadmap. Although it provided a clear, bird's eye view that can be used as a substantial entry point by practitioners, it is hypothesized that the model of the eSports industry proposed in the book is incomplete and can be extended with additional roles, noticeable in the industry.

A work published prior to Scholz's book, attempting to describe the logics of relationships in an eSports network was an exploratory study carried out by Zhou and Huang (2015) who had employed the e3-value methodology to analyze the business network built around the StarCraft 2 game. The authors examined data from multiple sources (e.g. threads on Reddit, Liquipedia, articles from the Internet, etc.) which allowed them to discern the network's actors (noteworthy, Scholz's classification was consistent with theirs) and translate their value offerings and revenue streams into the proposed model of the e3-value network. This perspective shed light on the general mechanics of the individual ecosystem built around the single game title, visualized its actors and explained how they contributed to and profit from the participation. Similarly, the actor model assumed by the authors was hypothesized to be subject to further extensions.

The third work categorized in the "network analysis" theme was a case study of the marketing strategy of the Paris Saint-Germain sports club by Chanavat (2017). The author carried out a number of interviews with a number of the company's insiders which allowed him to examine the interesting case of the entity's transformation into an "omnisports brand" - both traditional-sports and eSports. Nonetheless, the research did not satisfy the review's search objective as it did not touch upon the overall perspective on the eSports industry.

The literature review underpinned a formulated research question: what are the actors of the eSports industry and how do they interact with each other? To answer it, the research was drawn upon the industry's model proposed by Zhou and Huang and later by Scholz (see: Figure 1). 

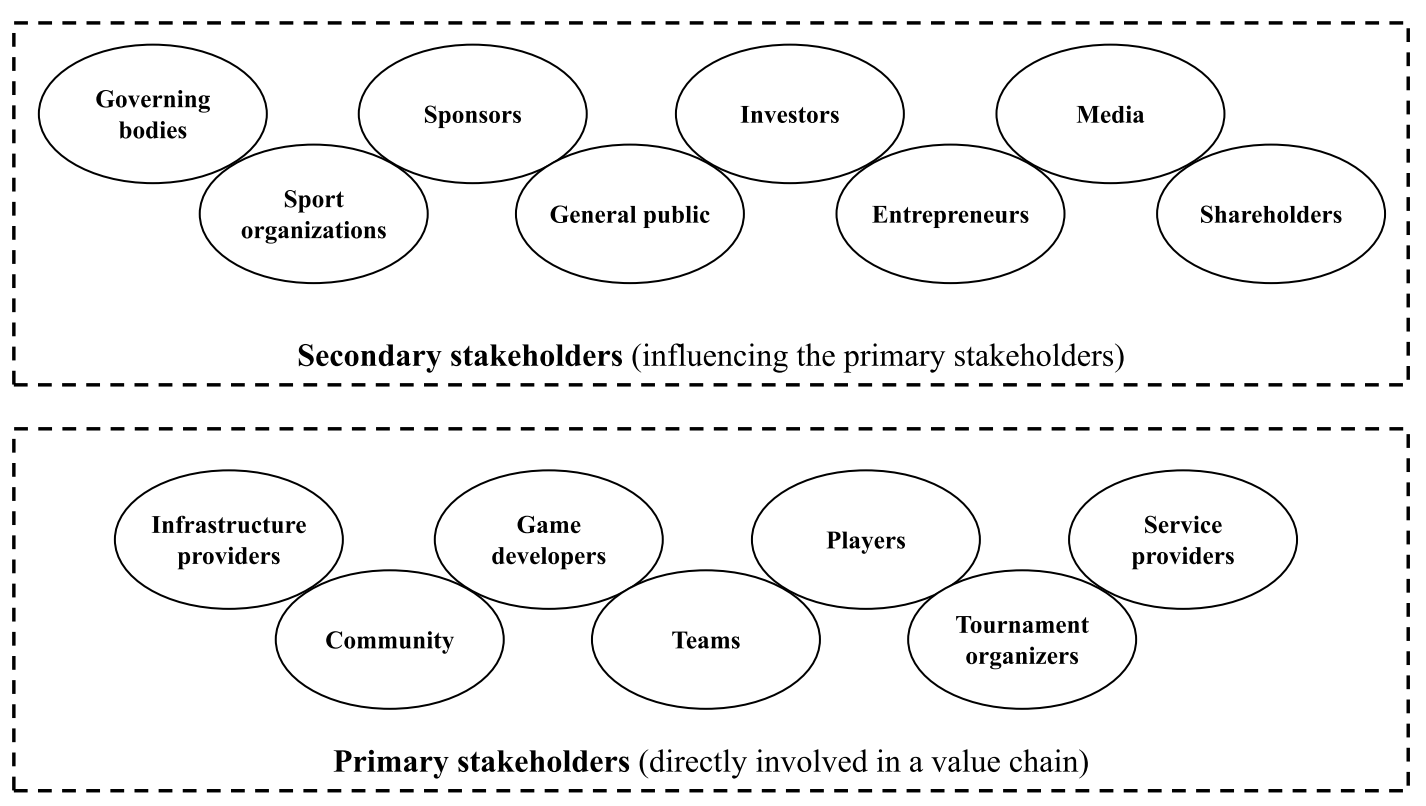

\section{Audience}

Figure 1. Categorization of an eSports network's participants proposed by Scholz based on Scholz (2019).

\section{Methodology}

The research used a multiple case study approach of analyzing social media content of a selection of eSports-related organizations (see Table 2). They were chosen to be distinguishable in terms of a self-assumed role. Thanks to the common practice of expressiveness in the social media space, observable in many electronic industries including eSports, it was not necessary to additionally filter candidates in terms of availability of data. In order to optimize further analysis of data by unifying the interface to data sources, the social media were limited only to Facebook profiles.

Table 2. The entities selected for the multiple case study. The descriptions were extracted from their own social media.

\begin{tabular}{|c|c|}
\hline $\begin{array}{l}\text { Facebook profile } \\
\text { name }\end{array}$ & Self-description \\
\hline FantasyExpo & $\begin{array}{l}\text { "The largest Polish gaming agency offering creative strategic consulting for } \\
\text { brands, unique marketing sales campaigns, as well as product and event } \\
\text { campaigns" (Fantasyexpo 2019). }\end{array}$ \\
\hline $\begin{array}{l}\text { WEST (Wrocław E- } \\
\text { Sports Tournament) }\end{array}$ & $\begin{array}{l}\text { "An eSports project co-created by a group of young people from IKSS - an } \\
\text { academic organization at Wrocław University of Economics and Business" } \\
\text { (WEST 2019) }\end{array}$ \\
\hline $\begin{array}{l}\text { ASE (Akademickie } \\
\text { Stowarzyszenie E- } \\
\quad \text { Sportowe) }\end{array}$ & $\begin{array}{l}\text { "League of Legends team representing Wrocław University of Technology" } \\
\text { (ASE 2019) }\end{array}$ \\
\hline
\end{tabular}

Posts from two-year period following the beginning were analyzed in search for all references and mentions about other entities and descriptions of their relationships. The posts often contained links to external sources (other website's, social media, images, and videos) which were recurrently scrutinized to obtain auxiliary insights on investigated events and actors. Altogether, the research covered over 500 posts and 100 additional items. 


\section{Results}

The data analysis confirmed Scholz's model as the authors were able to identify all the roles. However, it became evident on the course of the research that a part of the classified entities did not fall precisely under any category or could be labelled with a few of them. Consequently, the authors propose an extension to the model: four new roles and an alteration to the antecedent role of event organizer which, arguably, could be divided into two related but separate roles - main and supporting event organizer. The extended model is presented in Figure 2.
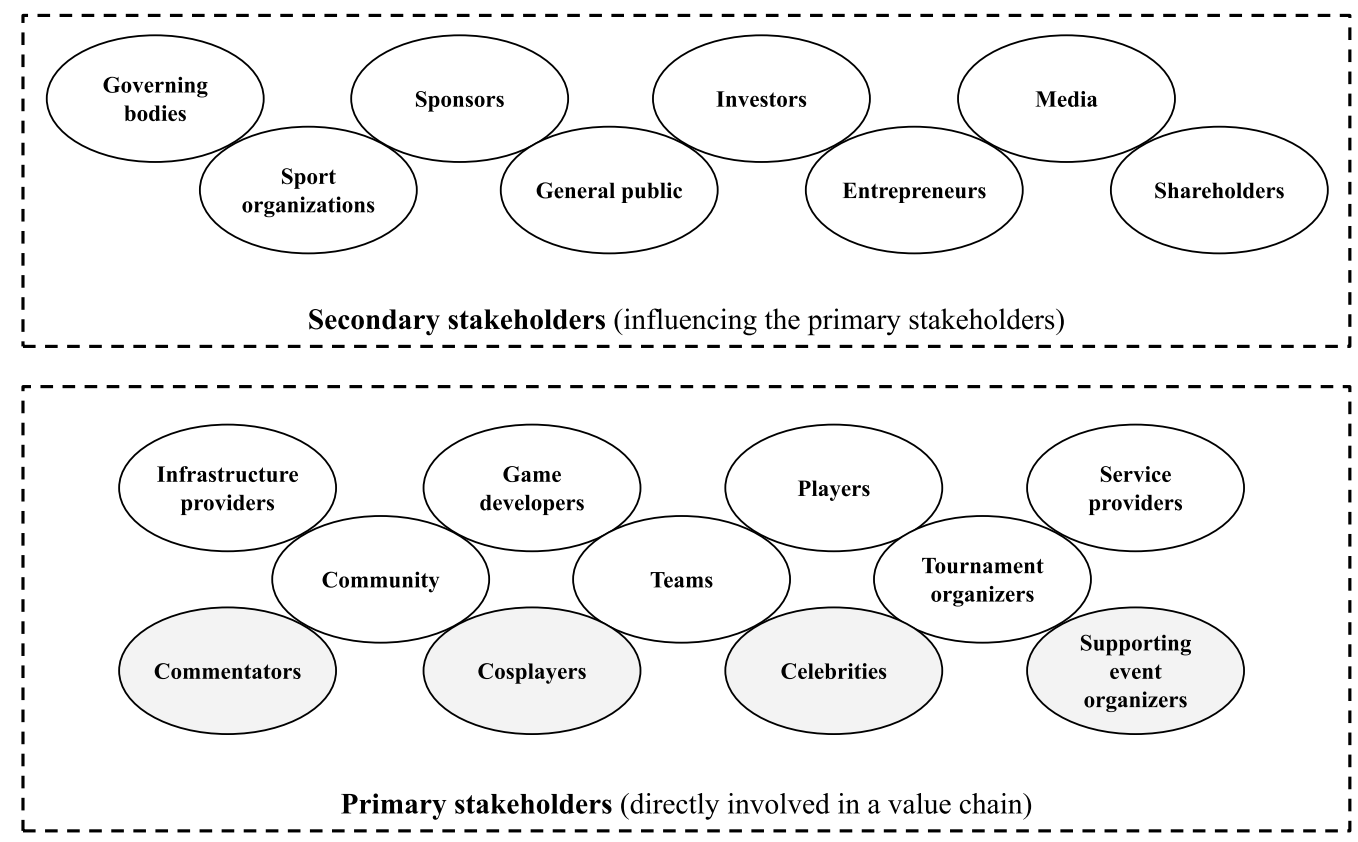

Audience

Figure 2. The extended model of the eSports industry proposed by the authors. The gray ellipses depict the roles additional to Scholz's model.

\subsection{Supporting event organizer}

The observed form of cooperation between event organizers in which there is one entity organizing the main event and a number of entities contributing to the event's agenda with their own performances paved a way to the proposed discrimination between the roles of the main event organizer and the supporting event organizer (see Figure 3). 


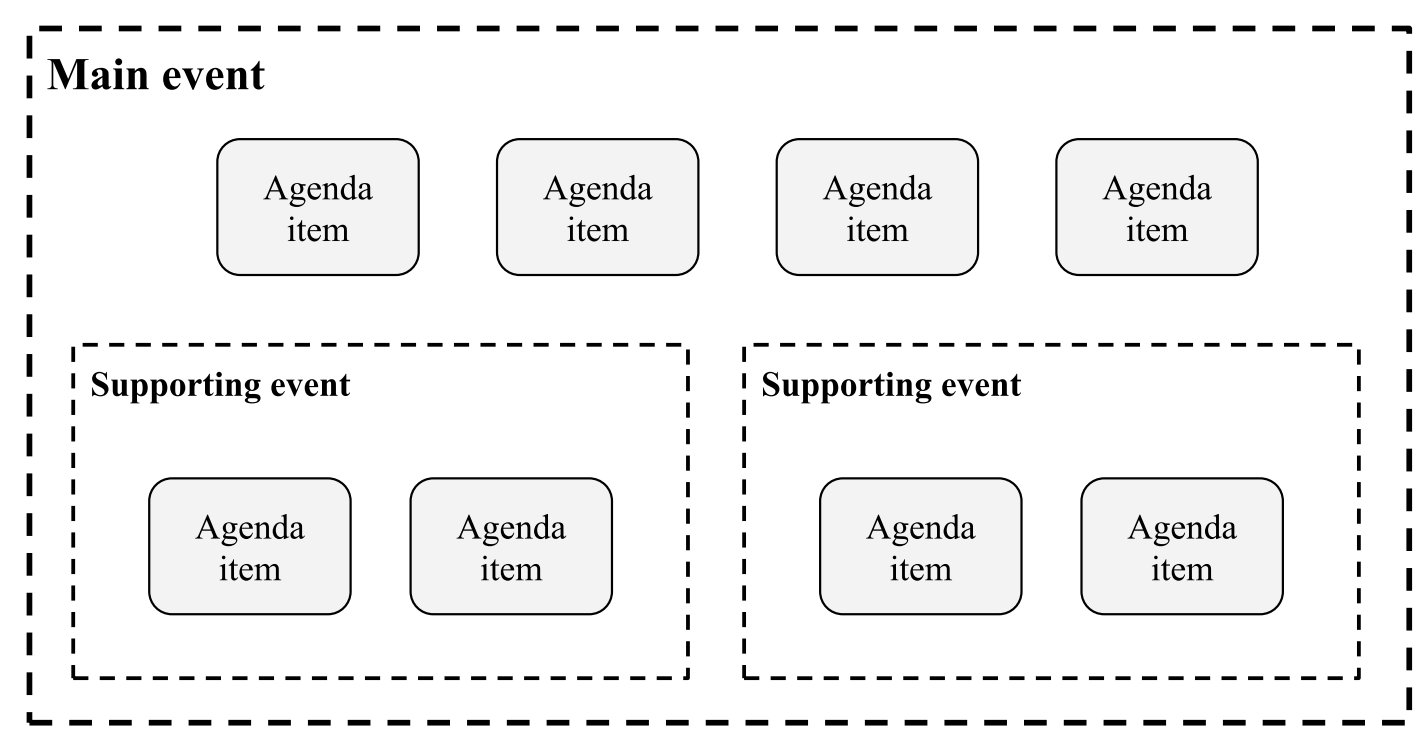

Figure 3. The cooperation scheme between the roles of main and supporting event organizers found by the research. Each event contained an agenda comprising individual items (e.g. different tournaments, an exhibition, a show, etc.) whereas the main event's agenda occasionally included a whole supporting event.

The supporting entities played a particularly significant part in young eSports networks, presumably due to scarcity of resources that could help to create an event by a single actor. Therefore, the organizers were observed to leverage the mutual benefits of the main and supporting event organizers. The main event organizer achieved its goal of expanding the core value stream whereas the supporting event organizer exploited the network effect of the event and gained access to potential customers and/or partners. In return, the supporting event organizers run individual agendas on their dedicated areas at the main event, contributed to the agenda with their speeches and presentations, or simply enriched the event with their brand stand. Moreover, their engagement usually meant broadcasting and advertising this fact in their own ego networks which further broadened the main event's outreach.

\subsection{Celebrity}

Celebrities play an important role in many events, not only eSports-themed. It was found that many traditional-sports spectators looked for famous players and their attendance at live events provides a way to fulfill this motive (Watanabe 2013). Similarly, a significant part of eSports spectators declared a motive for their interest in a specific player (Pizzo 2018). It was observed during the research that the event organizers often invited recognizable parties to enrich the overall experience, hereafter called the eSports celebrities. The figures sometimes contributed to the value stream with their stage performances or, in case of streamers (people recognized for their posted live videos) with their live streams of the event published on their official channels. Noteworthy, it was found that the celebrities cooperating with the event organizers to boost value proposition not necessarily limited to individual people. In the examined case, an event organizer (FantasyExpo) advertised a forthcoming event emphasizing the presence of a game developer (CD Projekt RED) widely recognizable by the target audience of game players for their flagship title (The Witcher). The event's participants were assured to be given a chance to interact with the organization during a Questions And Answers session constituting a part of the happening. This could be interpreted as one of the organization's inputs to the event's value stream.

\subsection{Cosplayer}

Cosplayers are described in the literature as people "role-playing with their costumes" or, in other words, dressing up as characters from games, comics, cartoons, anime, and other fictional universes 
(Winge 2006). As Winge pointed out, the "costumes" often included much more than mere clothes. Cosplayers modified their body (hair, piercings, etc.) and their character to maximize a non-verbal description of a roles they played which, for the time of the event, became their alter ego. Also, the clothes were rarely straightforward pieces of fabric but subject to extravagant creativity. They sometimes required a lot of resources and innovative tools (e.g. 3D printing, holograms, etc.) from their creators to be developed. For example, there were instances of cosplayers role-playing robotic characters (i.e. Transformers) which led to a costume being basically a state-of-the-art human-driven robot.

Cosplayers were observed to contribute significantly to the core value stream of eSports events, primarily by building the atmosphere and broadening the range of entertainment activities during the events. Certainly, cosplay is not only a supporting element of eSports but also an individual industry, featuring its own events and devoted audiences. In the context of this research, however, the "cosplay" role was only analyzed from the eSports-centric perspective and therefore it was not investigated individually. Nonetheless, it was found that entities participating in the eSports network as the "cosplay" actors went beyond Schultz's classification of the network's stakeholders and deserved their own, unique category.

\subsection{Commentators}

Another role interestingly rarely described in the literature, yet having a significant, direct impact on the core value stream of eSports events are commentators. They are - similarly to the traditional sports - highly fluent in the rules of a commented game individuals who comment tournament gameplays, making them more comprehensible by an average observer. It is rather evident that their competences in gameplay narration are paramount to the final reception of the gameplay. A highly skilled commentator can not only make complex, fast-moving gameplays easier to ingest by the audience but also provide insight on the current state of teams and players, their statistics, probable outcomes of the matches and the overall view on a tournament. On the other hand, an incompetent commentator may obfuscate reception of gameplay, confuse the audience with invalid insights on a tournament's state and, if not sufficiently fluent in common delicacy, may damage the event's image in the audience's eyes.

Commentators observed during the research were often well-known personas in the eSports and game communities. They usually represented their own brands of popular streamers, players, journalists, and other industry experts. Therefore, the events they commented could benefit from their recognizability and channels to their follower and partner networks. Such a cooperation between the main event organizer and the entity could be described with a dual role in the extended Scholz's classification of both commentator and celebrity and occasionally extended to a combination of commentator, celebrity and media in case the individual shared information about the event with own media channels.

A proper selection of commentators appears to be an important process that requires due diligence from the main event organizer, specifically with respect to their relations with certain parts of the public. There were numerous cases of public affronts by recognizable people from the game- and eSports-related communities which led to an outrage in some groups (Mitchell 2014) (Frank 2018). Admittedly, the caution should likewise apply to the selection of all celebrities branding an event with their own names.

\section{Discussion}

The study's findings provide an insight on the current state of the eSports industry from the network perspective. It leveraged expressiveness of modern IT-related organizations in the Internet and examined social media of a selection of eSports entities investigating their eSports-related environment. This allowed to identify and classify eSports actors operating in the network and led to a confirmation of the eSports industry's model previously proposed by Scholz. Additionally, the authors suggested an extension to Scholz's model (three additional roles: celebrity, cosplayer and commentator) along with division of the event organizer role into two separate ones: main and supporting 
event organizer. Lastly, the additional roles were characterized in accordance to the studied instances and related to the existing body of knowledge.

An obvious limitation of the research was its methodological scope. Expansion to more cases could result in a greater detail of the roles' descriptions and, presumably, lead to even greater complexity of the model. Another limitation was the data source which encompassed posts published by the entities (and their environment) on their own social media profiles. It means that they could miss (accidently or purposefully) certain intelligence that the entities had not consciously decided to inform the publicity about. Although this issue was partly addressed with the recurrent scrutiny of external, linked sources, interviews with insiders of the studied entities could bring added value.

The findings can help practitioners to understand and build network strategies in the emerging eSports industry as well as provide academics with a base model for future research. The authors intend to continue investigating the subject of eSports networks, strategies and business models and welcome fellow scientists and practitioners to join or provide a critical feedback.

\section{References}

ASE. 2019. ASE \& Inżynierzy PWr - Informacje. Available online: https://www.facebook.com/pg/AkademickieStowarzyszenieEsportowe/about/ (accessed on 23 December 2019).

BBC. 2017. E-sports to become a medal event in 2022 Asian Games. BBC Sports. Available online: https://www.bbc.com/news/technology-39629099 (accessed on 11 July 2019).

Chanavat Nicolas. 2017. French football, foreign investors: global sports as country branding. Journal of Business Strategy: 38(6), 3-10. https://doi.org/10.1108/JBS-04-2017-0053.

Darnall Nicole, Irene Henriques, and Perry Sadorsky. 2010. Adopting proactive environmental strategy: The influence of stakeholders and firm size. Journal of management studies: 47(6), 1072-1094. https://doi.org/10.1111/j.1467-6486.2009.00873.x.

Fantasyexpo. 2019. About us. Available online: https://www.fantasyexpo.pl/about-us/ (accessed on 29 November 2019).

Allegra Frank. 2018. Ninja responds to criticism of his refusal to stream with women. Available online: https:/www.polygon.com/2018/8/13/17686818/ninja-female-streamers-twitch-response (accessed on 24 October 2019).

IOC. 2018. Olympic movement, eSports and gaming communities meet at the eSports forum. Available online: https://www.olympic.org/news/olympic-movement-esports-and-gaming-communities-meet-at-theesports-forum (accessed on 11 July 2019).

Mitchell Ferguson. 2014. Esports journalist fired after anti-Polish tirade. Available online: https://dotesports.com/general/news/duncan-shields-thorin-poland-iem-fired-144 (accessed on 24 October 2019).

Newzoo. 2017. $2017 \quad$ Global Esports Market Report. Available online: http://resources.newzoo.com/hubfs/Reports/Newzoo_Free_2017_Global_Esports_Market_Report.pdf (accessed on 11 July 2019).

Newzoo. 2019. 2019 Global Esports Market Report. Available online: https://newzoo.com/insights/trendreports/newzoo-global-esports-market-report-2019-light-version/ (accessed on 11 July 2019).

Pizzo Anthony, Sangwon Na, Baker Bradley, Mi Ae Lee Doohan Kim, and Funk Daniel. 2018. eSport vs. Sport: A Comparison of Spectator Motives. Sport Marketing Quarterly: 27(2), 108-123.

Scholz Tobias. 2019. ESports is Business: Management in the World of Competitive Gaming. Cham: Palgrave Pivot.

Watanabe Yasuhiro, Matsumoto Koji, and Nogawa Haruo. 2013. Variables influencing spectators' desire to stay at a professional golf tournament in Japan. Contemporary Management Research: 9(3). https://doi.org/10.7903/cmr.10974.

WEST. 2019. O Nas. Available online: http://www.west-ikss.pl/ (accessed on 23 December 2019).

Winge Theresa. 2006. Costuming the imagination: Origins of anime and manga cosplay. Mechademia: 1(1), 65-76. https://doi.org/10.1353/mec.0.0084.

Zhou Feng, and Huang Shihui. 2015. Business models in e-sports: Starcraft 2. Paper presented at the International Conference on Electronic Business (ICEB), Hong Kong, December 6-10, pp. 129-139. Available online: http://iceb.johogo.com/proceedings/2015/ICEB-2015.pdf (accessed on 29 January 2020). 